\title{
Ser marrano em Minas Colonial
}

\author{
Anita Novinsky \\ Universidade de São Paulo
}

RESUMO

Baseado em 57 Processos inéditos de marranos (cristãos-novos, conversos) presos em Minas Gerais no século XVIII, este artigo procura mostrar seu papel na Idade de Ouro do Brasil. 64\% deles eram mercadores e $23 \%$ eram mineiros. Pertenciam à classe média e raros eram os magnatas. Nenhum dele esteve envolvido no tráfico negreiro. Acusados do crime de judaísmo e de pertencerem a sociedades secretas, representaram $42 \%$ dos brasileiros condenados à morte. Ser marrano entre os portugueses no Brasil mais um sentimento e uma visão de mundo do que uma prática religiosa.

Palavras-chave: marranos; Inquisição; cripojudaísmo.

\section{ABSTRACT}

Based on 57 unknown trials of marranos (new christians, conversos) arrested by the Inquisition in Minas Gerais in the XVIII the century, this article shows their role in shapping the history of Minas Gerais. 64\% of them were merchants na $23 \%$ were miners. Most of them belonged to a middle class and rare were those whit great fortunes. No one of them were engaged in slave trade. Acused of judaism and of participating in secret society the marranos of Minas represented $42 \%$ of the Brazilian burned at the stake. Being a marrano in Minas Gerais was not always being a crypto-new. Marranism in Brasil was a feeling and a approach to life.

Keywords: marranos; Inquisition; cryptojudaism. 
Minas Gerais foi no século XVIII uma das regiões mais procuradas pelos cristãos-novos portugueses. Cada nau que saía do Tejo trazia refugiados ou aventureiros cristãos-novos para o Brasil. Tomando conhecimento da prosperidade da região, do afluxo do ouro e das possibilidades confiscatórias, a Inquisição ordenou uma persistente fiscalização e algumas dezenas de portugueses foram presos, acusados de praticar a religião proibida: o judaísmo. Alguns já estavam estabelecidos nas regiões auríferas desde o início do século.

Este artigo é o extrato de um livro em elaboração sobre os marranos em Minas Gerais. Procuro aqui dar algumas pinceladas a esse quadro multicolor que foi a sociedade marrana mineira. Os dados que apresento baseiam-se todos em pesquisas colhidas em manuscritos ainda inéditos, principalmente nos processos de 57 prisioneiros, 11 dos quais já tinham nascido no Brasil.

Atualmente desenvolvo uma nova história sobre Minas, procurando analisar a sociedade nas suas dobras ocultas e dar a conhecer a origem judaica dos mineiros e seu comportamento, que fugia aos padrões obrigados pela Igreja. Quem foram os primeiros povoadores marranos de Minas, os fundadores das primeiras vilas do ouro, os construtores dos primeiros arraiais e principalmente o que pensavam? Que imagens do mundo transmitiam, como se explica de um lado a forte resistência ao catolicismo e de outro seu completo desaparecimento?

162 Somente a análise minuciosa da documentação manuscrita permitirá desvendar o lado oculto da sociedade marrana brasileira, e corrigir mal entendidos e erros interpretativos. É lamentável que a experiência marrana no Brasil não faça parte ainda dos livros de história e que continue totalmente ignorada pelos historiadores estrangeiros.

Os cristãos-novos ou marranos que desbravaram as selvas, cultivaram a terra, apresaram índios, guerrearam os jesuítas, foram homens totalmente diferentes dos judeus de origem ashkenazi, assim como dos conversos sefaradins que se dispersaram pela Itália, Holanda, França ,norte da África, Levante e outros lugares do mundo. Falar dos cristãos-novos generalizando sua atuação e sua mentalidade tem levado a uma concepção errônea do que foi o fenômeno marrano, especificamente o brasileiro.

Na primeira metade do século XVIII foram presos algumas dezenas de cristãos-novos de Minas Gerais acusados de judaísmo. ${ }^{1}$ Com exceção das profundas e exaustivas pesquisas genealógicas feitas por José Gonçalves Salvador, a historiografia brasileira nada praticamente apresenta de científico sobre as atividades econômicas e a vida cotidiana e social dos marranos em Minas Gerais. ${ }^{2}$ Eminentes historiadores brasileiros, por não utilizarem as fontes inquisitoriais minimizaram ou ignoraram o papel que representaram os descendentes dos judeus na colonização do Brasil, tanto do ponto de vista econômico, como social e cultural. 
A afirmação de eminente historiador de que "raramente se encontravam em Minas Gerais processos contra cristãos-novos por práticas judaizantes," precisa hoje ser reconsiderada. ${ }^{3}$ Existe uma numerosa documentação sobre Minas Gerais nos arquivos do extinto Tribunal da Inquisição em Portugal, que revela uma presença considerável de colonos de origens judaicas, condenados por praticas religiosas ou por suas idéias.

Afastados há mais de um século da cultura judaica e altamente assimilados, o estilo de vida aventureiro e violento dos marranos brasileiros diferencia-se fundamentalmente daquele vivido pelos judeus em outras regiões. Para dar um exemplo da atuação dos cristãos-novos ou marranos no contexto político e social mineiro, quero lembrar três personagens de origens judaicas que se destacaram na vida política e administrativa: Garcia Rodrigues Pais, Miguel Telles da Costa e Manuel Nunes Viana. Garcia Rodrigues Pais era filho de Fernão Dias Pais, o "caçador de esmeraldas" ,e foi responsável pela organização da primeira expedição desbravadora e fundadora de Minas Gerais, constrindo o chamado "Caminho Novo", conhecido também como "Caminho do Comércio".

Esse caminho abreviava consideravelmente a distância do Rio de Janeiro, porto de onde afluíam as principais mercadorias de Portugal para Ouro Preto. Em 1702, Garcia Rodrigues Pais Leme, em recompensa aos serviços prestados a Coroa foi nomeado "Guarda Mor Geral das Minas", e obteve o título de fidalgo da Casa Real, o que lhe conferiu tão grande prestigio que o levou a solicitar em 1710 sua admissão à prestigiosa Ordem de Cristo. O ingresso lhe foi recusado por ser infamado de "cristão-novo por parte de sua avó materna". ${ }^{4}$ A legislação discriminatória e o preconceito contra os descendentes de judeus chegou a atingir os portugueses e brasileiros até a $5^{a}$ e $6^{a}$ geração. Temos poucas noticias sobre os sentimentos judaicos de Garcia Rodrigues Pais Leme, pois nunca foi preso pela Inquisição. Apesar de no Brasil a luta pela sobrevivência ter abrandado as barreiras que separavam cristãos-velhos dos cristãos-novos, estes, devido às suas críticas às imposições econômicas e ideológicas da Metrópole eram vistos com desconfiança pela governança portuguesa. Mas havia um fator decisivo que facilitava o ingresso dos cristãos-novos nas elites locais: o volume de seus bens. No Brasil podia-se, através da riqueza, "branquear a pele" e "apagar a mancha" do sangue judeu.

O segundo personagem que nos primórdios da história de Minas exerceu importante cargo administrativo foi o capitão-mór Miguel Teles da Costa, sobre o qual temos numerosas notícias, pois foi preso pela Inquisição em 1713 e acusado de judaísmo. ${ }^{5} \mathrm{O}$ monarca português o havia nomeado capitão-mor das vilas de Itanhaen, Ilha Grande e Parati. Era proprietário de terras em Nossa Senhora do Carmo, sendo um dos primeiros povoadores da região. Fazia parte da socie- 
dade secreta de cristãos-novos, constituída por um grupo de comerciantes e mineradores residentes no Rio das Mortes, entre os quais também encontramos o cristão-novo Francisco Matheus Rondon, guarda mor do Rio das Mortes. Miguel Teles da Costa foi preso no Rio de Janeiro juntamente com outros cristãos-novos, acusados todos de serem adeptos da Lei de Moisés. Mercador de posses enviava produtos coloniais para seus sócios em Lisboa, sendo um deles seu irmão Francisco Mendes de Castro. Do Rio de Janeiro também mandava "carregações" para as Minas Gerais, auxiliado por seu sobrinho Diogo Lopes Flores. Em 1704 enviou 20 ou mais cargas de fazendas para o Rio das Mortes, região de onde se extraía grande quantidade de ouro. Tinha plantações de milho e feijão, possuía escravos negros e cavalos, armas e diversos bens móveis, conforme consta de seu inventário. ${ }^{6}$ Construiu sua residência fixa em Rio das Mortes que depois transformou em estalagem, onde se abrigavam seus companheiros que vinham negociar nas Minas. Miguel Teles da Costa foi a principal autoridade da região, cuidava da defesa e supervisionava a entrada nas Minas, onde só era permitida a penetração com "licença especial". Em certa ocasião foi "recriminado" por ter favorecido a entrada de "certas pessoas", provavelmente cristãos-novos,"sem licença". Apesar de todo seu prestígio e de ter sob sua jurisdição as terras mineiras, não conseguiu fugir dos agentes da Inquisição que rondavam a região. Preso, levado aos cárceres inquisitórias, torturado, teve toda sua fortuna confiscada. Saiu em auto-de-fé em Lisboa e morreu louco e indigente.

Um terceiro personagem, dos mais curiosos da história colonial, foi o cristão-novo Manuel Nunes Viana. ${ }^{7}$ Sobre sua personalidade violenta, estranha, paradoxal e seu envolvimento numa guerra civil com os paulistas pela posse das terras mineiras temos notícias detalhadas. Mas sobre suas crenças sabemos muito pouco .De origens judaicas, era amigo íntimo de Miguel de Mendonça Valladolid, homem de negócios que percorria as rotas do comércio São Paulo, Rio de Janeiro, Minas, Bahia, Colônia do Sacramento, e que lhe ensinou as orações judaicas. Nasceu em Viana do Castelo e fez fortuna na Bahia e Minas Gerais comerciando escravos e ouro. Em 1710 era proprietário de várias e lucrativas minas de ouro em Caeté e outras regiões e tinha o monopólio do abastecimento de carne para as Minas Gerais. Foi líder, em 1708, da facção mineira na sangrenta "guerra dos Emboabas". Participou em um verdadeiro massacre no Capão da Traição, quando numerosos paulistas, cristãos-novos e velhos, foram mortos. Ficou conhecido na história do Brasil como o "Rei dos Emboabas", e foi aclamado governador interino de toda região mineira. Apesar de suas desavenças com o Vice-Rei, recebeu Carta de Mercê do Rei de Portugal pelos seus "relevantes serviços". Excepcionalmente foi aceito na prestigiosa e elitista Ordem de Cristo 
não obstante sua origem judaica, o que mostra a arbitrariedade com que se aplicavam as "leis de limpeza".

Manuel Nunes Viana, mal era alfabetizado mas tinha algumas ambições culturais. Depois de vitorioso financiou, em 1728, a publicação de um livro de Nuno Marques Pereira "Compêndio do Peregrino da América, obra que teve enorme sucesso. Consta que tinha uma biblioteca e também chegou a financiar a impressão de $3^{\circ}$ volume das Décadas de Diogo do Couto. Manuel Nunes Viana vivia como muitos cristãos-novos, dividido entre dois mundos. Num deles pronunciava as preces judaicas, no outro levava suas duas filhas para serem freiras em um convento de Lisboa.

A ocupação do território em terras mineiras se processou diferentemente de outras regiões da América. As oportunidades de enriquecer e ascender nas Minas eram muitas, mais fáceis e mais rápidas que na sociedade açucareira. Os cristãos-novos espalhados por todo território brasileiro mantinham entre si uma ampla rede de comunicações, e o fato de estarem dispersos pela América e pelo mundo abriu-lhes uma frente para as transações econômicas com a qual os cristãos-velhos dificilmente podiam competir. Portugal exercia um controle rigoroso sobre a região, principalmente devido ao intenso contrabando nos portos brasileiros e a massa de aventureiros estrangeiros que procurava chegar ao território sem licença. Parece que os cristãos-novos conheciam algumas facilidades para se chegar às Minas. ${ }^{8}$

Nas regiões mineiras da Bahia, do Rio de Janeiro e de Goiás, cristãos-novos estavam envolvidos nas mais diversas atividades. Compravam e vendiam escravos e gêneros necessários para os moradores, eram pecuaristas e abasteciam de carne toda a região. Trabalhavam na extração do ouro, eram artesãos, e havia entre eles alguns médicos e advogados. Adquiriam livros e escreviam poemas. ${ }^{9}$

Examinando os documentos referentes às profissões e à declaração dos bens confiscados pela Inquisição aos cristãos-novos em Minas Gerais, encontramos $23 \%$ dos condenados dedicando-se à mineração, sendo que $64 \%$ aparecem como comerciantes e $6 \%$ como agricultores ${ }^{14}$ Os mais prósperos cristãos-novos do ponto de vista econômico, eram aqueles cujas atividades combinavam a mineração, lavoura e o comércio de escravos e mercadorias diversas. Em Ouro Preto por exemplo, no ano de 1740 , as maiores fortunas se concentravam nas mãos de cristãos-novos que combinavam simultaneamente diversas ocupações. Assim Ignacio Dias Cardoso vem mencionado como agricultor, negociante, mineiro e dono de plantações de milho e feijão. Era proprietário de 2 engenhos possuindo extensões de terras nas quais explorava o mineral, chegando a acumular uma fortuna de 26;295\$311 réis. Contudo, de um modo geral, são poucos os cristãos-novos que aparecem com fortuna comparável à do magnata Francisco Ferreira Izi- 
dro, que chegava a 10;709\$000 réis ou de Manuel de Albuquerque e Aguilar, talvez o mais rico dos cristãos-novos, com 57;330\$000 réis. ${ }^{10}$

Uma avaliação inicial e aproximada dos bens que foram confiscados aos cristãos-novos condenados em diversas regiões do Brasil, baseada em 130 inventários que publiquei, foi feita pelo infatigável pesquisador sobre marranos, tragicamente desaparecido, Flávio Mendes de Carvalho. ${ }^{11}$ Os resultados que apresenta podem trazer alguma luz sobre as condições financeiras de um certo número de marranos brasileiros: 78\% dos 129 condenados que analisou, pertenciam à classe media e apenas 5,4\% eram grandes magnatas que contribuíram com 52\% dos bens que foram confiscados, sendo que quase a metade do total proveio dos senhores de engenho. Parece, segundo essa avaliação, que os mais ricos eram os cristãos-novos que viviam na Bahia, seguidos pelos do Rio de Janeiro e em terceiro lugar vem os de Minas Gerais. Analisando apenas 129 casos, o patrimônio médio, avaliado em ouro, que foi confiscado entre 1704 e 1761 por Capitania foi:

Bahia - 48.846 gramas de ouro

Rio de Janeiro - 44.927 gramas de ouro

Minas Gerais - 35.850 gramas de ouro

Goiás - 17.119 gramas de ouro

Pernambuco - 5.484 gramas de ouro

Paraíba - 2.646 gramas de ouro

São Paulo - 2.106 gramas de ouro ${ }^{12}$

$\mathrm{O}$ rei D. João V, durante seu reinado, recebeu uma renda de 379 toneladas de ouro provenientes do Brasil. ${ }^{13}$

O sistema que impulsionou a estrutura econômica na América Lusitana foi, como sabemos, a escravidão. O tráfico de escravos tornou-se a atividade comercial mais rentável na colônia e contratadores, autorizados pela Coroa portuguesa, traziam negros que já eram esperados por mercadores cristãos-novos nos portos do Rio de Janeiro e Bahia. Nesses portos faziam seus carregamentos e os levavam para as Minas onde os revendiam, em geral a crédito. José Gonçalves Salvador, que publicou um trabalho sobre os "magnatas do tráfico negreiro" afirma que esses traficantes eram principalmente cristãos-novos, mas não apresenta nenhuma documentação que prove essa constatação. Suas conclusões se apoiam apenas na evidência dos nomes mais comuns entre os cristãos-novos. ${ }^{14}$ É totalmente impossível tirarmos qualquer conclusão sobre a origem cristã-velha ou cristã-nova dos luso-brasileiros baseando-nos em evidência onomástica, uma vez que todos nomes dentre os cristãos-novos encontram-se também entre os cristãos velhos.

Tomando ainda como fonte, dentre centenas de cristãos-novos que foram 
presos no Brasil, apenas os bens declarados por cento e trinta cristãos-novos, encontrei na primeira metade do século XVIII, vinte e cinco cristãos-novos residentes ou assistentes nas Minas Gerais. ${ }^{15}$ Nenhum destes vinte e cinco cristãosnovos declarou ser traficante de escravos. Constam como compradores, vendedores e transportadores de "carregações" de uma região para outra do Brasil. Não devemos confundir comerciantes de escravos com os "contratadores", grandes capitalistas que faziam as viagens para a África em busca de negros, muitas vezes em barcos próprios ou através de agentes.

Interessante que, também no Rio de Janeiro, entre os 71 cristãos-novos por mim inventariados, não encontrei nenhum que trouxesse carregação de escravos de ultra mar. Apenas a Bahia aparece como exceção: entre vinte e um presos inventariados, três traficavam negros da África: José da Costa que ia buscá-los em Angola e na Costa da Mina, Antônio Cardoso Porto, também chamado Belchior Mendes Corrêa, que os trazia da Costa da Mina e Tomás Pinto Corrêa ,que trazia "carregações" de negros de Angola mas que pertenciam a "várias pessoas". ${ }^{16}$

Os laços familiares eram condição fundamental nas transações comerciais realizadas pelos cristãos-novos nas Minas. Os conhecidos mercadores Davi de Miranda, Damião Rodrigues Moeda, Francisco Nunes de Miranda, João de Moraes Montesinhos, entre muitos outros, negociavam sempre ligados aos seus parentes.

A mobilidade dos cristãos-novos na colônia brasileira foi freqüente e ininterrupta. Apesar de encontrarmos famílias radicadas durante gerações nas mesmas regiões, de um modo geral a população cristã-nova apresentava uma grande instabilidade. A vigilância constante a que estavam expostos por parte dos agentes inquisitoriais, muitas vezes impedia a sua radicação, mas foram também interesses econômicos que os levavam a residir temporariamente em vários lugares. Francisco Nunes de Miranda, por exemplo, tinha casa na Bahia, Rio de Janeiro e Rio das Mortes e fazia negócios com o magnata Francisco Pinheiro e com seu parente José da Costa que trazia escravos da Costa de Marfim e Angola para o Brasil.

Contrabando, fraudes, roubos era o cotidiano das Minas, mas no ano de 1725 seu grau foi alarmante. O próprio governador, D. Lourenço de Almeida foi um infatigável contrabandista de diamantes. Tanto cristãos velhos como cristãosnovos realizavam o tráfico ilegal, que no tempo não era visto como uma grave contravenção moral, mas comumente aceito nas práticas comerciais e encarado como parte inerente das atividades metropolitanas e coloniais. ${ }^{17} \mathrm{Na}$ corte, nos mares, nos mercados, padres da Igreja, homens de Estado, mercadores, mineiros, senhores de engenho, lojistas, profissionais e artesãos aceitavam a prática do contrabando como algo inevitável. ${ }^{18}$ A Metrópole procurou continuamente, sem 
sucesso, controlar essas fraudes. As denúncias eram graves, principalmente sobre uma "casa da Moeda" ilegal, clandestina, na qual aparece também envolvido o rico cristão-novo Manuel de Albuquerque Aguilar .

Apesar do estágio inicial em que se encontram as investigações sobre a população cristã-nova em Minas Gerais, podemos dizer que seu número foi relativamente alto, uma vez que incluía também os "assistentes" que residiam no Rio de Janeiro e na Bahia, mas que passavam longos períodos em Minas Gerais. No "Livro dos Culpados", que é a principal fonte para o conhecimento da população cristã-nova no Brasil, encontramos anotados os nome de todos os cristãosnovos suspeitos, denunciados ou que foram presos. Nele estão registrados 150 cristãos-novos residentes ou assistentes em Minas Gerais. ${ }^{19} \mathrm{O}$ número de cristãos-novos em algumas cidades do Brasil ultrapassou o número de judeus que viviam em Amsterdã no período de sua maior efervescência econômica e cultural. Mas devemos ter em mente, que somente é possível obter dados demográficos sobre cristãos-novos em determinadas regiões do Brasil, através da contagem daqueles que foram presos pela Inquisição ou a ela denunciados como judaizantes. O número total será portanto sempre impreciso, pois a maior parte dos cristãos-novos que vieram para o Brasil não foram presos, e diluíram-se em meio a população brasileira. Em Minas Gerais arrolamos, até o presente, aproximadamente 500 cristãos-novos entre denunciados e presos.

Analisando apenas 57 condenados de Minas Gerais temos o seguinte quadro:

O maior número de prisões de cristãos-novos foram feitas nos anos de grande produção aurífera 1728, 1729, 1730, 1732 e 1734, sendo seu número mais alto em 1728 e 1729 ,com 8 prisioneiros cada ano. No Brasil foram queimados 21 cristãos-novos ( 2 em estátua e 19 em carne) .Entre os queimados em carne, 8 residiam ou "assistiam" em Minas Gerais, isto é aproximadamente $42 \%$. Dos prisioneiros do Brasil somente os acusados de judaísmo receberam como sentença a pena de morte.

Foram queimados "em carne” em Minas Gerais :

1. Miguel Mendonça Valadolid 1731

2. Diogo Corrêa do Valle 1732

3. Luís Miguel Corrêa 1732

4. Domingos Nunes 1732

5. Manoel da Costa Ribeiro 1737

6. Luís Mendes de Sá 1739

7. Martinho da Cunha Oliveira 1747

8. João Henriques 1748 
Entre os 57 cristãos-novos mencionados, não incluí o judaizante cabalista Pedro Rates Henequim, queimado em 1748, que havia vivido 20 anos em Minas Gerais, porque as "investigações de genere" o deram como cristão-velho, mas não temos sobre sua origem, muita certeza. ${ }^{20}$

A história dos marranos de Minas Gerais, como de todo o Brasil, revela, como já escrevi, grande diversidade de comportamento, uma rebeldia frente a Igreja e uma ânsia de liberdade que se expressa tanto entre os que judaizavam como entre os laicos.

Examinando os processos de Diogo Corrêa do Vale e seu filho Luiz Corrêa, ambos presos em Minas Gerais, temos confirmada a opinião do padre Antônio Vieira, sobre o funcionamento do Tribunal e a inocência dos réus. Diogo nasceu em Sevilha e residia no Porto. Doutor em medicina pela Universidade de Coimbra, já viúvo e devido à prisão de vários membros de sua família pela Inquisição, fugiu com o filho para o Brasil, onde se estabeleceu em Vila Rica de Ouro Preto. Foi preso em 12 de setembro de 1730, junto com seu filho Luiz Miguel Corrêa. ${ }^{21}$ Numa carta enviada pelo familiar do Santo Ofício, Dr. Lourenço de Valadares Freire aos senhores Inquisidores, datada de Vila Rica no ano de 1730, ficamos conhecendo os sentimentos de Luiz Miguel Corrêa. Quando o Tenente Martinho Alvarez o prendeu, murmurou: "dizem que o Santo Ofício é reto, agora vejo que não, porque prende aos homens inocentes." 22 sados de "judaizar"há mais de 20 anos, quando ainda viviam no Porto. Os Inquisidores não conseguiram juntar nenhuma prova de judaísmo contra ambos, durante os anos em que viveram em Minas. A prisão de Diogo se deve a intrigas e antigas rivalidades de seus colegas do Porto e sobre divergências que tinham quanto ao tratamento que devia ser dado aos doentes. Alguns amigos tentaram interceder a seu favor, confirmando sua reta conduta e sua caridade como cristão e como médico, que "atendia doentes pobres sem cobrar". Diogo também tentou se defender afirmando, até o fim, serem falsas todas as acusações, mas os Inquisidores não alteraram sua sentença de morte. Diogo insistiu ter sempre vivido na Lei de Cristo nela querendo morrer, mas o que foi decisivo na sua sorte foi sua origem judaica. ${ }^{23}$

O destino de Luiz Miguel Corrêa foi tão triste quanto de seu pai. Com fortes inclinações para a vida religiosa, seu apego a fé cristã transparece em todo seu julgamento. Querendo tornar-se sacerdote, procurou o Bispo do Rio de Janeiro pedindo que o ajudasse. O Bispo logo o desiludiu, mostrando-lhe quão inúteis eram seus sonhos de entrar para a Igreja, uma vez que era cristão-novo e tinha tantos membros de sua família presos pelo Santo Ofício. Numa desesperada e última tentativa Luiz disse ao Bispo que estava disposto a vender todos seus es- 
cravos e bens para pagar a compra do "exame de limpeza de sangue", "como tantos faziam". Foi inútil. Na última sessão de seu julgamento rogou aos Inquisidores que, mesmo se acreditassem na sua inocência e o declarassem, o condenassem a cárcere perpétuo, para que assim pudesse tratar de sua salvação "já que não podia ser frade pela impureza de seu sangue”. Dizia ainda que o medo da morte o pusera em tal "desesperação" que o levou a confessar de si e denunciar outras pessoas "falsamente", afirmando que eram praticantes da Lei de Moisés. Até o último momento Luís declarou-se inocente do crime que o acusavam, ser judeu. Foi queimado na mesma tarde que seu pai. ${ }^{24}$

É importante ressaltar que em Minas Gerais como no restante do Brasil, ser acusado de judaísmo não se resumia apenas em seguir algumas leis dietéticas, observar os jejuns, abster-se do trabalho aos sábados, ou obedecer alguns outros preceitos ordenados pela religião judaica. O marranismo entre os portugueses no Brasil foi em grande parte uma atitude mental, um sentimento, uma postura frente a vida. ${ }^{25}$ Se a maioria dos cristãos-novos no Brasil conseguiu ultrapassar as barreiras discriminatórias legais impostas pela sua origem e sangue, ou a discriminação social, e se diluir na sociedade ampla, houve uma parte que permaneceu marginal e se manteve fiel a tradições, mesmo que apagadas, herdadas dos seus antepassados. A transmissão da memória de uma história vivida e sofrida durante séculos, juntamente com a exclusão legal e social a que estavam sujeitos, reforçou entre os cristãos-novos a resistência na adoção dos preceitos da Igreja, e criou entre eles uma postura crítica frente à religião católica. A crítica religiosa foi a grande contribuição que os cristãos-novos no Brasil deram ao pensamento ilustrado do século XVIII.

Outro exemplo de um mineiro dissidente é o caso de Diogo Nunes Henriques, rico homem de negócios, preso nas Minas em $1728 .{ }^{26}$ Cometeu o crime de afirmar que "cada um podia viver ou morrer na Lei que melhor the parecesse". Levou-o aos cárceres de Lisboa sua afirmação sobre a liberdade de consciência, impensável entre a maioria de seus contemporâneos portugueses. Os Inquisidores ao receberem essa denúncia imediatamente mandaram investigar "de que terra era natural", seu "modo" de vida, "em que parte" de Minas morava, e sua "reputação de sangue". Novas "informações" se acumularam, inclusive a de que sua casa em Ouro Preto era sede da sociedade secreta de cristãos-novos, onde se reunia uma verdadeira elite mineira: David Mendes, Domingos Nunes (sobrinho de Diogo Nunes Henriques), o senhor de engenho Domingos Rodrigues Ramires que tinha residido no Rio de Janeiro, João da Cruz, o mercador de panos David de Miranda, Francisco Nunes, Duarte Rodrigues, Manuel Nunes de Paz (filho de Diogo Henriques), Manuel Nunes Sanches e muitos outros, todos vizinhos. 
O retrato que nos ficou de Diogo Nunes Henriques é o de um homem letrado que se tornou suspeito pelo fato de ser "dado a ler alguns livros". Cristãos-velhos, que testemunharam contra ele, afirmaram nunca tê-lo visto rezar, nem ensinar aos seus escravos a doutrina cristã, como era costume na roça. Um alfaiate afirmou aos agentes investigadores que "nunca viu Diogo com um rosário de contas, e que se desobrigava do preceito da quaresma, ensinando essas heresias aos seus escravos". Diogo também chamava a atenção de seus vizinhos cristãos velhos, pois, quando cansado, suspirava, Ai! Deus! e nunca pronunciava o nome de Jesus. O crime ainda mais grave: reunia seus amigos, entre eles vários membros da família Miranda, "para lerem livros". ${ }^{27}$

No processo de Domingos Nunes, um sobrinho de Diogo Nunes Henriques, também encontramos interessantes informações sobre o cotidiano dessa sociedade secreta mineira. ${ }^{28}$ Foi emitida contra ele uma ordem de prisão, datada do ano de 1728, mas a Inquisição já estava à sua procura desde o anos de 1726. Só foi encontrado 2 anos e 7 meses depois da ordem de prisão e entregue a Inquisição de Lisboa em 12 de outubro de 1730. Denunciaram-no 17 companheiros de negócios, que comerciavam com o Brasil e que foram todos presos: Gaspar Fernandes Ferreira, (ou Pereira), homem de negócios de Ouro Preto; Miguel da Cruz, homem de negócios que residia simultaneamente no Rio de Janeiro; Manuel Nunes da Paz, homem de negócios morador em Minas; Gaspar Henriques, mineiro da Bahia; Manoel Nunes Bernal, capitão de navio morador no Rio de Janeiro; Jerônimo Rodrigues, tratante morador na Bahia; Joseph da Cruz Henriques, dizimeiro-mor, morador no Ribeirão do Carmo; Joseph Rodrigues Cardoso, sem oficio, natural da Bahia e morador em Ribeirão do Carmo; Diogo Nunes Henriques, homem de negócios, morador em Ouro Preto e tio de Domingos Nunes; Antônio da Fonseca Rego, lavrador de cana, natural de Pernambuco, morador em Paracatu; Antônio Rodrigues Campos, lavrador de mandioca, morador na Bahia; Diogo Dias Corrêa, sem oficio, morador em Santos; Luiz Vaz de Oliveira, natural da Espanha e morador em Ribeirão do Carmo; David Mendes da Silva, morador em Ouro Preto; Miguel Henriques, mercador em Ribeirão do Carmo. ${ }^{29}$

Os negócios internos que os cristãos-novos faziam no Brasil obrigavamnos a viajar pelas mais distantes regiões, o que levou à criação de verdadeiras redes comerciais. Para isso precisavam de apoio e confiança, o que lhes vinha dos seus secretos amigos cristãos-novos, mesmo sabendo que, se presos, todos se denunciariam, uns aos outros.

O "judaísmo" de que foi acusado Domingos Nunes deixa o historiador com enormes dúvidas, mas parece que desde sua infância fora doutrinado na fé judaica. Tinha uma casa montada em Minas, para onde trazia "carregações" com mercadorias diversas. Cruzava continuamente diversas regiões da colônia, mantendo 
contatos com os principais mercadores. Quando o puseram na tortura, Domingos acusou todos seus companheiros que viviam nas regiões de Caeté, Cachoeira, Paraopeba, Congonhas, Vila Pitangui, arraial de Antônio Pereira, minas do Fanado, Serro Frio, Rio das Mortes, além de muitos do Rio de Janeiro, Bahia, Santos. Domingos também procurou utilizar-se de diversas estratégias para salvar sua vida, mas acusaram-no os "espias" que haviam sido encarregados de vigiar seu cárcere durante 24 horas, de que havia "jejuado judaicamente”, olhando o céu e ter feito "gestos judaicos". Ainda mais "de escrever algo secretamente numa taboa de seu estrado e logo apagar o que tinha escrito para que ninguém o lesse". Domingos, depois de ter justificado todos seus atos, inclusive de não ter comido no cárcere porque queria matar-se, acabou como todos os réus, confessando sua cumplicidade no crime de judaísmo. ${ }^{30}$

As diversas sociedades marranas secretas que se criaram em Minas Gerais acompanharam a rota do ouro. Em cada vila do ouro ou arraial que se fundava, organizavam-se imediatamente os encontros clandestinos. Essas reuniões secretas se realizavam principalmente em algumas casas de Ouro Preto, Tijuco (a zona dos diamantes), Rio das Mortes, Ribeirão do Carmo. Aí se articulavam os negócios e se confirmava a confiança e aí também se construiu, ao mesmo tempo, uma força de resistência aliada e um sentimento do mundo, que foi o Marranismo . Dessa sociedade subterrânea faziam parte cripto-judeus, laicos, céticos, homens que se identificavam não sempre pela fé ou comportamento, mas pela sua condição de excluídos e por suas criticas à religião católica. Essas sociedades secretas das Minas, com seus cripto-judeus e seus descrentes, não foi um fenômeno novo, mas a continuidade de um longo processo, já amadurecido depois de dois séculos de experiências vividas e transmitidas no Brasil. Nasceu com a formação dos primeiros núcleos populacionais, logo após o descobrimento do Brasil, em S. Vicente, São Paulo, na Bahia, em Pernambuco e se espalhou pela colônia a medida em que era desbravado o território e chegavam os novos colonos, aventureiros, fugitivos das perseguições inquisitoriais de Portugal.

Uma vez desvendada a rota do ouro, os Inquisidores ordenaram que fossem procurados os moradores de origens judaicas, e as principais zonas visadas foram também as mais prósperas, o Rio de Janeiro e Minas Gerais. Nesse mesmo tempo deu-se uma intensa busca de cristãos-novos na Paraíba, sendo presos aproximadamente 49 lavradores, a maioria ligada à produção de açúcar.

A perseguição dos cristãos-novos de Minas Gerais acompanhou o mesmo modelo adotado, durante os dois séculos anteriores, em todo império português: atingiu aqueles cristãos-novos cujos pais, avós, irmãos já tinham passado pelos cár- 
ceres de Lisboa, sendo que muitos pertenciam às mais antigas famílias da colônia, aí já radicadas desde os séculos 16 e 17.

As práticas judaicas em Minas Gerais mencionadas nos processos inquisitórias, aparecem revestidas de um forte simbolismo. As comunicações secretas eram feitas muitas vezes através de códigos. De uma maneira geral as cerimônias eram as mesmas que as praticadas pelos cristãos-novos em Portugal e na América Espanhola ou em outras regiões do Brasil: vinham calcadas nas tradições com algumas omissões e alguns sincretismos. Concentravam-se principalmente nos jejuns do Yom Kipur, na guarda do sábado, na comemoração da Páscoa e na festa chamada da "rainha Ester", acompanhadas de algumas restrições alimentares. A idéia de um Deus Único, criador do Universo e as rejeições da salvação pela lei de Cristo, das imagens e da confissão, completam o quadro da religiosidade marrana. O principal divisor das águas entretanto foi a questão do Messias, que estudo em outro trabalho.

Com Max Weber, podemos repetir que a necessidade religiosa dos marranos respondia a necessidade de uma compensação. A memória da história passada, do exílio da Babilônia até a Inquisição, acompanhada da promessa e esperança de redenção, ofereceu aos portugueses de origens judaicas uma justificativa para existir e para o seu contínuo sofrimento. O desejo de "pertencer" uniu crentes e laicos e perdurou durante 3 séculos, desafiando as mais pesadas ameaças erguidas pelo sistema político-religioso português.

A história dos cristãos-novos em Minas Gerais, ao mesmo tempo em que apresenta similaridades com o fenômeno marrano em Portugal e outras regiões do Brasil, contem algumas especificidades. O seu estudo implica no conhecimento, tanto das peculiaridades regionais e conjunturais como da bagagem cultural que os portugueses trouxeram de suas origens judaicas.

\section{NOTAS}

${ }^{1}$ Os nomes dos 57 prisioneiros de Minas Gerais são inéditos e foram microfilmados no ano de 1965, quando uma Bolsa da Fundação Calouste Gulbenkian me permitiu passar um ano pesquisando nos Arquivos Portugueses. As cópias de alguns processos foram cedidas a alunos de pós-graduação, na base das quais elaboraram suas dissertações de Mestrado. A lista completa, com os números de seus respectivos processos, constam do artigo de Novinsky, Anita "Marranos and the Inquisition on the Gold Route in Minas Gerais, Brazil" in The Jews and the Expansion of Europa to the West, 1450-1800" New York/Oxford: Bergham Books, Oxford, 2001, pp. 215-241 e também em Novinsky, Anita, Prisioneiros Brasileiros na Inquisição, Rio de Janeiro: Expressão e Cultura, 2001. (a sair)

${ }^{2}$ SALVADOR, J. Gonçalves. Os cristãos-Novos em Minas Gerais durante o Ciclo do Ouro. São Paulo, Pioneira, 1992.

${ }^{3}$ LIMA Júnior, Augusto. A Capitania de Minas Gerais. Belo Horizonte: Itatiaia, 1978.

${ }^{4}$ Habilitação da Ordem de Cristo, Letra G, Maço 6, no 66, apud SALVADOR, Op. cit. p. 7 nota 1. Existe uma denúncia contra certo Garcia Rodrigues Paes Leme, datada do ano de 1796, por ter pre- 
gado desobediência a Igreja. Inquisição de Lisboa nº5529, Arquivo Nacional da Torre do Tombo, manuscrito.

${ }^{5}$ Inquisição de Lisboa $n^{0}$ 6.515, Arquivo Nacional da Torre do Tombo, manuscrito. Veja BROMBERG, Raquel Mizrahi. A Inquisição no Brasil: Um capitão-mór judaisante. São Paulo: Ed. Centro Estudos Judaicos, USP ,1984.

${ }^{6}$ NOVINSKI Anita. Inquisição, Inventários de Bens Confiscados a Cristãos-Novos no Brasil - século XVIII. Lisboa: Imprensa Nacional/Casa da Moeda, 1978, pp.223-224.

${ }^{7}$ Sobre Manoel Nunes Viana, veja “o Processo de Miguel de Mendonça Valladolid, Inquisição de Lisboa 9.973". Lisboa, Arquivo Nacional da Torre do Tombo, manuscrito e Manuscritos não catalogados "caixa 676, século XVIII, anos 1703-1710, 29 janeiro 1710 e caixa 83, ano 1719. Lisboa, Arquivo Histórico e Ultramarino, manuscritos. Veja também SALVADOR, J. Gonçalves. Os cristãos-novos, op. cit., p. 11.

${ }^{8}$ Um Tratado intitulado Itinerário Geográfico impresso na Tipografia de Antônio da Silva em 1732, de autoria de Francisco Torres de Brito, era clandestinamente distribuído e dava instruções de como chegar às Minas. Uma cópia desse itinerário encontra-se na John Carter Brown Library, Providence, Rhode Island.

${ }^{9} \mathrm{O}$ primeiro poeta que aparece na região das Minas, no século XVIII, é Antônio Ferreira Dourado, preso pela Inquisição em Vila Boa de Goiás. Foi condenado no auto de fé de 1761 a Cárcere e Hábito Penitencial a Arbítrio dos Inquisidores. Inquisição de Lisboa, processo no 6.268. Lisboa, Arquivo Nacional da Torre do Tombo, ms. A Inquisição lhe confiscou $24 \mathrm{~kg}$. de ouro.

${ }^{10}$ Veja LEWKOWICZ, Ida. "Confiscos do Santo Ofício e formas de riquezas nas Minas Gerais no século XVIII”. In Inquisição. Ensaios sobre Mentalidade, Heresia e Arte. (org.) Anita Novinsky e Maria Luiza Tucci Carneiro. São Paulo: Expressão e Cultura/EDUSP, 1992, pp. 208-224.

${ }^{11}$ Inquisição. Uma Avaliação de Bens Confiscados a Judeus Brasileiros - século XVIII. Exemplar único, datilografado, oferecido pelo autor à Anita Novinsky e nunca publicado.

${ }^{12}$ Idem.

${ }^{13}$ Idem.

${ }^{14}$ SALVADOR, J. Gonçalves. Os Magnatas do Tráfico Negreiro. São Paulo: Pioneira, 1981.

${ }^{15}$ NOVINSKY, Anita. Inquisição. Op. cit.

${ }^{16}$ Idem, pp. 157,168 e 247.

${ }^{17}$ PIJNING, Ennest. Controling Contraband: Mentality, Economy and Sociey in Eighteenth Century. Rio de Janeiro. Doctor Dissertation. John Hopkins University, 1997.

${ }^{18}$ Idem.

${ }^{19}$ NOVINSKY, Anita. Rol dos Culpados. Rio de Janeiro: Expressão e Cultura, 1992.

${ }^{20}$ NOVINSKY, Anita.'The Inquisition and the Mythic World of a Portuguese Cabalist in the $18^{\text {th }}$, century". In Proceedings of the Eleventh World Congress of Jewish Studies. Jerusalém, pp. 115-122, 1994.

${ }^{21}$ Sobre Diogo Correa do Valle, veja NOVINSKY, Anita. "A Inquisição no Brasil, Judaisantes ex-alunos da Universidade de Coimbra”. In Universidade. História. Memória. Perspectivas. Actas do $4^{\circ}$ Congresso de História da Universidade, $7^{\circ}$ centenário. Coimbra, pp. 315-327, 1991.

${ }^{22}$ Processo de Luís Miguel Correa. Inquisição de Lisboa no 9.249. Arquivo Nacional da Torre do Tombo, ms. 
${ }^{23}$ Processo de Diogo Correa do Vale. Inquisição de Lisboa n 821. Arquivo Nacional da Torre do Tombo, Lisboa, ms.

${ }^{24}$ Processo de Luis Miguel Correa, op. cit.

${ }^{25}$ Veja MORIN, Edgard. Mes Démons. Paris: Ed. Stock, 1994, pp. 138-184 e NOVINSKY, Anita. "A critical Approach to the Historiography of Marranos in the light of New Documents". In Studies on the History of Portuguese Jews from their Expulsion in 1947 through their Dispersion. co-ed. Israel Katz and M. Mitchell Serels, New York: The American Society of Sephardic Studies, 2000, pp. 107-118.

${ }^{26}$ Processo de Diogo Nunes Henriques. Inquisição de Lisboa no 7.487. Arquivo Nacional da Torre do Tombo, ms

${ }^{27}$ Idem.

${ }^{28}$ Processo de Domingos Nunes. Inquisição de Lisboa no 1779. Arquivo Nacional da Torre do Tombo, ms.

${ }^{29}$ Idem.

${ }^{30}$ Idem.

Artigo recebido em 06/2000. Aprovado em 11/2000. 